\title{
Avaliação dietética das refeições ofertadas aos colaboradores de empresa cadastrada no Programa de Alimentação do Trabalhador
}

\section{Dietetic evaluation of meals provided to co-workers of a company registered in the Workers' Food Program}

Rosevane de Oliveira Cunha' Roseane Moreira Sampaio Barbosa²

' Curso de especialização em Gestão da Qualidade em Alimentação para Coletividade, Universidade Federal Fluminense. Niterói-RJ, Brasil.

${ }^{2}$ Faculdade de Nutrição, Universidade Federal Fluminense. Niterói-RJ, Brasil.

Correspondência / Correspondence Roseane Moreira Sampaio Barbosa E-mail: roseanesampaio@ig.com.br

\section{Resumo}

Objetivo: Avaliar os aspectos dietéticos das refeições oferecidas aos colaboradores de uma empresa de construção civil inscrita no Programa de Alimentação do Trabalhador (PAT). Método: Foi realizada avaliação dietética das refeições ofertadas durante o almoço e as variáveis analisadas foram: valor energético total, percentual de macronutrientes, e de gorduras saturadas e poliinsaturadas, além da quantidade de colesterol (mg), sódio $(\mathrm{mg})$ e fibras alimentares $(\mathrm{g})$. Calcularam-se também o net dietary protein calories e a quantidade de frutas, verduras e legumes (FLV). Os valores encontrados foram comparados aos atuais parâmetros nutricionais preconizados pelo programa. Os valores de colesterol, ácidos graxos poli-insaturados e quantidade de FLV foram comparados com as recomendações da OMS (2003). Resultados: Verificou-se que as refeições ofertadas aos colaboradores encontraram-se acima do recomendado para energia, proteínas, sódio e colesterol. Em contrapartida, houve oferta adequada de fibras alimentares e FLV. Conclusão: $O$ almoço ofertado na unidade de alimentação e nutrição não atende a todos os parâmetros nutricionais preconizados pelo PAT. Dessa forma, faz-se necessário adotar programas de promoção de saúde com enfoque na prática de hábitos alimentares saudáveis.

Palavras-chave: Programas e políticas de nutrição e alimentação. Saúde do Trabalhador. Alimentação Coletiva. Nutrientes. Dietética. 


\section{Abstract}

Objective: Evaluating dietary aspects of meals provided to co-workers of a civil construction company registered in the Workers' Food Program (PAT). Method: An evaluation was done of meals provided for lunch and variables analyzed were: total energy value, percentage of macronutrients, and saturated and polyunsaturated fat, besides the amount of cholesterol (mg), sodium (mg) and dietary fiber (g). It was also calculated the Net Dietary Protein Calories and the amount of fruits, legumes and vegetables (FLV). Results: The values found were compared with current nutritional parameters recommended by the program. Cholesterol values, polyunsaturated fatty acids and the amount of FLV were compared with recommendations from WHO (2003). It was found that meals provided to co-workers were above the recommendation to energy, protein, sodium and cholesterol. On the other hand, it was provided an adequate supply of dietary fiber and FLV. Conclusion: Lunch provided at food and nutrition unit does not satisfy every nutritional parameters recommended by PAT. So it is necessary to follow health promotion programs that focus the adoption of healthy eating habits.

Keywords: Programs and policies of food and nutrition. Worker's Health. Collective Feeding. Nutrients. Dietetic.

\section{Introdução}

A necessidade de alimentar adequadamente a classe trabalhadora brasileira sempre esteve relacionada com a produtividade do seu trabalho. Nesse contexto, surgiram a partir da década de 1930, políticas de alimentação e nutrição na área de alimentação do trabalhador, já que o mesmo precisava estar bem alimentado para exercer suas atividades profissionais. ${ }^{1}$

Com a evolução das políticas públicas de alimentação e nutrição, em 1976 foi criado o Programa de Alimentação do Trabalhador (PAT), que busca estimular o empregador a fornecer alimentação nutricionalmente adequada aos trabalhadores, por meio da concessão de incentivos fiscais, tendo como prioridade o atendimento aos trabalhadores de baixa renda. ${ }^{2}$ O PAT tem por objetivo melhorar as condições de saúde dos trabalhadores, aumentar a produtividade dos mesmos e reduzir o número de faltas e acidentes de trabalho. ${ }^{3}$ 
Ao longo dos anos, o ocorreram diversas alterações no programa, tanto na sua sistemática interna de subsídios, quanto na exigência ao atendimento das necessidades nutricionais dos trabalhadores de empresas nele cadastradas. Essas mudanças nos parâmetros nutricionais ocorreram, principalmente, devido à transição nutricional da população brasileira. Antes, estas eram restritas às recomendações de energia e proteínas e inadequadas ao atual perfil epidemiológico e nutricional da população brasileira. ${ }^{4}$

No ano de 2006, os parâmetros nutricionais do PAT foram alterados a partir da publicação da Portaria Interministerial no 66 , por meio de um trabalho conjunto entre os Ministérios do Trabalho e Emprego, da Fazenda, da Saúde, da Previdência Social e do Desenvolvimento Social e de Combate à Fome, tendo como abordagem a segurança alimentar e nutricional. Com a implementação desta portaria, passaram a ser estabelecidos valores de macro e micronutrientes recomendados diariamente, a fim de fornecer ao trabalhador uma alimentação balanceada, nutritiva e de valor energético que garanta sua saúde. ${ }^{5}$

Em função do grande número de trabalhadores beneficiados pelo PAT e considerando que esses passam grande parte de seu tempo de vida no ambiente de trabalho, o programa pode ser considerado estratégico na promoção da alimentação saudável, melhorando a qualidade de vida do trabalhador. Nesse contexto, é relevante a avaliação dietética das refeições realizadas pelos colaboradores de empresas cadastradas no PAT.

\section{Materiais e Métodos}

estudo exploratório realizado com técnica de observação direta do porcionamento da refeição "almoço" servida aos colaboradores de duas empresas do ramo de construção civil que formam um consórcio para a construção do Complexo Petroquímico do Estado do Rio de Janeiro (COMPERJ), localizado no município de Itaboraí, região metropolitana do estado do Rio de Janeiro. O consórcio, com aproximadamente 1.800 funcionários, atua no segmento da construção civil e sua população é constituída por soldadores, montadores de andaimes, pedreiros e ajudantes, administradores, técnicos, operadores, motoristas, dentre outros. Estes desempenham atividades do tipo moderada, leve ou pesada.

Os colaboradores realizam uma pequena refeição (desjejum) e uma grande refeição (almoço) no local de trabalho. O almoço é composto por: acompanhamento (arroz e feijão), guarnição, prato principal com opção, saladas (três tipos), sobremesa (doce ou fruta) e suco. O serviço de distribuição é do tipo "self-service", exceto para o prato principal e a sobremesa, sendo os mesmos porcionados por funcionário do serviço de alimentação. 
Os sujeitos do estudo foram os colaboradores que aceitaram participar da pesquisa e que assinaram o Termo de Consentimento Livre e Esclarecido. A pesquisa foi aprovada pelo Comitê de Ética em Pesquisa da Faculdade de Medicina do Hospital Universitário Antônio Pedro, sob o número CAAE: 0256.0.258.000-11. Período do estudo: novembro de 2011 a junho de 2012.

A avaliação dietética da refeição (almoço) oferecida foi realizada pelo método de observação direta do porcionamento das preparações distribuídas aos colaboradores. Realizou-se inicialmente a padronização do peso médio das porções das preparações com os respectivos utensílios que foram utilizados pelos colaboradores, antes de a UAN ser aberta ao público. Foram obtidas três porções de cada uma das preparações, em três diferentes medidas: cheio(a), médio(a), raso(a) ou grande, médio e pequeno. A pesagem das porções alimentares foi realizada em uma balança eletrônica com capacidade máxima de $2 \mathrm{~kg}$. Esse processo foi cuidadosamente observado para todos os alimentos e porções servidas, e os dados coletados foram anotados em formulário próprio previamente elaborado.

A análise da composição nutricional das refeições servidas foi determinada utilizando a Tabela de Composição dos Alimentos; ${ }^{6}$ inexistindo algum alimento, foi utilizada a Tabela para Avaliação de Consumo Alimentar em Medidas Caseiras. ${ }^{7}$ No entanto, quando o alimento não constava em nenhuma das tabelas, foram utilizadas as informações nutricionais que constavam no rótulo dos mesmos.

Os dados obtidos foram inseridos em planilhas do Microsoft Excel para análise estatística dos resultados apresentados. Foram determinados: o valor energético total, o percentual de macronutrientes, e de gordura saturada e poliinsaturada, além da quantidade de colesterol (mg), sódio (mg) e fibras alimentares (g). Foram calculados também o NDPcal\% (Net Dietary Protein Calories), que é o percentual fornecido pela proteína líquida em relação ao valor calórico total do cardápio, e a quantidade de frutas, verduras e legumes (FLV) (g). Foi utilizada a estatística descritiva (média, desvio padrão, coeficiente de variação) para comparação dos dados dietéticos. Os valores encontrados foram comparados aos parâmetros nutricionais preconizados pelo PAT; ${ }^{5} \mathrm{e}$ para a quantidade de FLV, colesterol e gordura poli-insaturada, foram utilizados $40 \%$ dos valores da recomendação da Organização Mundial da Saúde (OMS). ${ }^{8}$

Como os parâmetros nutricionais do PAT não oferecem margem de variação para os macronutrientes (carboidratos, proteínas e gorduras totais), conforme outras recomendações, utilizaram-se para classificar a adequação das refeições os seguintes 
valores: para os nutrientes carboidratos, proteínas e gorduras totais, foram considerados os valores recomendados mais 0,9 - isto é de $60-60,9 \%$, de $15-15,9 \%$ e de $25-25,9 \%$, respectivamente; para gorduras saturadas, foram considerados adequados os cardápios que apresentaram este nutriente menor ou igual a 10\%; para os que apresentavam margem de variação - isto é, ácidos graxos polinsaturados, fibras alimentares, sódio e NdPcal -, foi considerado o valor do limite superior mais 0,9. Quanto ao teor energético, foram considerados adequados aqueles que se apresentaram dentro do intervalo de 600 a 800 Kcal e adicional de $400 \mathrm{Kcal}$ permitido pelo PAT em função do tipo de atividade ocupacional desempenhada

A determinação da amostra teve como base o modelo para dados discretos considerando a prevalência para desnutrição de 1,4\% e 3,1\% para homens e mulheres, respectivamente e, analogamente para obesidade de $13 \%$ e 17,5\%, segundo a Pesquisa de Orçamentos Familiares (POF), com nível de confiança de $95 \%$ e precisão de 5\%, considerando população infinita. ${ }^{9}$

\section{Resultados}

Participaram do estudo 150 trabalhadores, $86,6 \%$ do gênero masculino e 13,4\% do gênero feminino. A tabela 1 apresenta a comparação dos parâmetros nutricionais das refeições oferecidas no almoço segundo o $\mathrm{PAT}^{5}$ e a OMS. ${ }^{8}$ Verificou-se que as refeições ofertadas aos colaboradores encontraram-se acima do recomendado para energia, proteínas, sódio e colesterol.

Observando-se a tabela 1, o valor energético total apresentou-se acima do valor recomendado pelo PAT ( 600 a $800 \mathrm{Kcal}$ e adicional de $400 \mathrm{Kcal}$ mediante justificativa). Foi observado, ainda, que apenas $33 \%$ dos trabalhadores apresentaram consumo médio de energia adequado (tabela 2). Em relação aos macronutrientes, a oferta de carboidratos nas refeições analisadas esteve próxima ao recomendado (tabela 1), no entanto, apenas $18 \%$ das refeições apresentaram a quantidade recomendada de carboidratos (tabela 2). A contribuição das proteínas em relação ao VET encontrou-se acima do padrão recomendado pelo PAT. No que se refere à refeição oferecida para cada colaborador, $22 \%$ das refeições apresentaram a quantidade recomendada deste nutriente. Em relação à quantidade de calorias proveniente exclusivamente das proteínas (NdpCal), percebeuse que a média semanal dos cardápios estava de acordo com as recomendações do PAT. 
Os resultados deste estudo estão de acordo com a recomendação do PAT para gorduras totais (tabela 1), mas quando se analisa a refeição oferecida para cada colaborador, verificou-se que somente $11,3 \%$ das refeições atendiam ao que é preconizado pelo programa (tabela 2). Observaram-se baixa oferta de gorduras poli-insaturadas, oferta adequada de gorduras saturadas e elevada oferta de colesterol em relação às recomendações preconizadas pela $\mathrm{OMS}^{8}$ (tabela 1). Os teores de sódio nas refeições ofertadas também foram muito elevados (tabela 1), sendo que apenas 5,3\% das refeições estavam com a quantidade recomendada (tabela 2).

A quantidade de fibras alimentares nas refeições estava acima do que é estabelecido pelo programa, sendo que a maioria das refeições encontrava-se com quantidades adequadas de fibras alimentares (tabela 2). A oferta de frutas, legumes e verduras mostrou-se próxima à recomendação da $\mathrm{OMS}{ }^{8}$

Tabela 1. Comparação dos parâmetros nutricionais na refeição oferecida aos trabalhadores de uma UAN, segundo recomendações de $\mathrm{PAT}^{5}$ e $\mathrm{WHO}^{8}$. Itaboraí-RJ, 2012.

\begin{tabular}{ccccc}
\hline Parâmetros nutricionais & Média & $\begin{array}{c}\text { Desvio } \\
\text { padrão }\end{array}$ & $\begin{array}{c}\text { Coeficiente } \\
\text { de Variação }\end{array}$ & Recomendação \\
\hline Energia (kcal) & 1372 & 380,1 & 0,27 & $600-800^{*}$ \\
Carboidratos (\%) & 56,7 & 8,6 & 0,15 & $60^{*}$ \\
Proteínas (\%) & 18 & 3,7 & 0,20 & $15^{*}$ \\
Gorduras totais (\%) & 25,2 & 8 & 0,32 & $25^{*}$ \\
Gorduras saturadas (\%) & 7,2 & 2,7 & 0,37 & $<10^{*}$ \\
Fibras alimentares (g) & 23,1 & 7,6 & 0,33 & $7-10^{*}$ \\
NDPCal (\%) & 10,91 & 5,17 & 0,47 & $6-10^{*}$ \\
Sódio (mg) & 2426,4 & 872,2 & 0,35 & $720-960 *$ \\
Colesterol (mg) & 160,7 & 50,4 & 0,3 & $120 * *$ \\
Gorduras poliinsaturadas (\%) & 5,7 & 2,7 & 0,4 & $6-10 * *$ \\
FLV (g) & 166 & 119,1 & 0,7 & $160 * *$ \\
\hline
\end{tabular}

$\mathrm{n}=150$ *PAT; **WHO(2003) 
Tabela 2. Percentual de refeições servidas aos colaboradores que atenderam às recomendações, segundo $\mathrm{PAT}^{5}$ e $\mathrm{WHO}^{8}$. Itaboraí-RJ, 2012.

\begin{tabular}{ccc}
\hline Parâmetros nutricionais & $\mathrm{n}$ & Adequação das refeições \% \\
\hline Energia (kcal) & 49,5 & 33 \\
Carboidratos & 27 & 22 \\
Proteínas & 33 & 11,3 \\
Gorduras totais & 16,9 & 77,3 \\
Gorduras saturadas & 115,9 & 98,67 \\
Fibras alimentares & 148 & 10,97 \\
NDPCal & 16,4 & 5,3 \\
Sódio & 7,9 & 10,6 \\
Colesterol & 15,9 & 83 \\
Gorduras & 124,5 & 50 \\
poliinsaturadas & 75 & \\
FLV & &
\end{tabular}

$\mathrm{n}=150 * \mathrm{PAT} ; *$ WHO(2003).

\section{Discussão}

No presente estudo, observou-se inadequação da oferta de energia (1372 kcal), mesmo quando se admite um acréscimo de $400 \mathrm{Kcal}$ permitido pelo programa, desde que seja justificado. Esses resultados assemelham-se ao estudo de Mattos, ${ }^{10}$ que analisando o cardápio do almoço de uma empresa localizada no Rio de Janeiro, concluiu que o mesmo estava acima do recomendado em relação ao VET. A oferta de energia considerada excessiva para uma única refeição também foi encontrada em estudos realizados em algumas indústrias petroquímicas participantes do PAT no estado da Bahia, cujas refeições atendiam quase à totalidade das necessidades energéticas diárias do indivíduo. ${ }^{11}$

A ingestão energética acima das necessidades individuais é uma das principais causas do aumento da prevalência do sobrepeso, da obesidade e das doenças crônicas não transmissíveis (DCNT) associadas, tais como diabetes mellitus, hipertensão arterial e doenças cardiovasculares. ${ }^{12}$ 
No que diz respeito à oferta de carboidratos, observou-se que esta se assemelha à recomendação do PAT, embora apenas $18 \%$ das refeições tenham apresentado oferta adequada deste macronutriente. O percentual de carboidratos foi superior ao encontrado por Bandoni et al., ${ }^{4}$ que constataram média de 50,9\% ao avaliarem o cardápio de 72 empresas filiadas ao PAT na cidade de São Paulo. No estudo de Vanin et al., ${ }^{13}$ o consumo de carboidratos esteve acima do recomendado, sendo ingerida pelos clientes uma média de $63,3 \%$.

Com relação à oferta de proteínas, observou-se que a mesma estava acima do valor preconizado pelo PAT. Resultados similares foram encontrados por Souza et al., ${ }^{14}$ que ao avaliarem os cardápios de cinco empresas situadas no município de Caruaru-PE, encontraram alto percentual de proteínas nas refeições. Refeições hiperproteicas também foram observadas por Amorim et al., ${ }^{15}$ que analisaram o almoço servido a participantes do PAT numa empresa na cidade de Santa Luzia-MG.

O consumo excessivo de proteínas está relacionado à sobrecarga da função renal e ao desenvolvimento de doenças crônicas, devido à ingestão de gordura saturada e de colesterol encontrado nos alimentos de origem animal. Por esse motivo, seu consumo deveria ser restringido às quantidades recomendadas, suficientes para assegurar o suprimento das necessidades de proteínas. ${ }^{16}$

Em relação à quantidade de calorias provenientes exclusivamente das proteínas (NdpCal), percebeu-se que as refeições estão de acordo com as recomendações do PAT. Esses valores são inferiores aos encontrados por Rocha et al., ${ }^{17}$ que analisaram os cardápios de três empresas na região do grande ABC no estado de São Paulo, e encontraram percentual médio de 14,9\% para NdpCal. Resultados similares também foram encontrados por Souza et al., ${ }^{14}$ sendo que este valor foi de $22,5 \%$.

As refeições ofertadas estavam adequadas em relação às gorduras totais, mas quando se analisa a oferta individual, percebe-se que somente 11,3\% dos usuários atenderam ao que é preconizado pelo programa (figura 1). Castro et al., ${ }^{12}$ ao avaliarem o padrão dietético de uma empresa metalúrgica do Rio de Janeiro, encontraram valor médio de 21,8\% de lipídeos. Em relação à oferta de gorduras, a média de consumo de gordura saturada foi de $7,2 \%$, dentro dos limites estipulados pelo PAT, que é de menos de $10 \%$. A adequação do percentual lipídico no presente estudo se deve, em parte, à baixa frequência de frituras nos cardápios ofertados. Ressalta-se que quando há presença de fritura no prato proteico principal, a opção é sempre cozida, assada ou grelhada, e muitas vezes os colaboradores preferem estas preparações. 
Observou-se baixa oferta de gorduras poli-insaturadas $(5,7 \mathrm{mg})$ e elevada oferta de colesterol (160,7 mg) em relação às recomendações preconizadas pela $\mathrm{OMS}^{8}$ (tabela 1). Resultados similares foram apresentados por Bandoni et al., ${ }^{4}$ que encontraram ingestão de gorduras poli-isaturadas abaixo da adequação (3,87 mg). Segundo Amorim et al., ${ }^{18}$ os teores de lipídeos devem ser mantidos na faixa recomendada, privilegiando os óleos vegetais, ricos em ácidos graxos poli-insaturados, e diminuindo o consumo de gorduras animais, fontes de ácidos graxos saturados e colesterol.

Os estudos epidemiológicos têm fornecido evidências sobre a importância da dieta como fator de risco para doenças cardiovasculares. Vários alimentos e nutrientes têm sido relacionados à ocorrência de doenças crônicas em diferentes populações, destacando-se o consumo excessivo de colesterol e gorduras saturadas, nutrientes implicados na gênese das doenças cardiovasculares. ${ }^{18}$

O sódio esteve mais que o dobro acima das recomendações do PAT e apenas 5,3\% das refeições apresentavam quantidade recomendada (figura 1). Esses resultados são similares aos achados de Salas et al., ${ }^{19}$ que ao avaliarem os teores de sódio em uma UAN no município de Suzano-SP, constataram que o consumo médio de sódio foi de $2.435 \mathrm{mg}$. Resultados semelhantes foram encontrados por Martins et al., ${ }^{20}$ que analisaram a oferta de sódio em preparações do almoço de uma Unidade de Alimentação e Nutrição (UAN) hospitalar. O per capita de sódio ofertado no almoço encontrava-se elevado, totalizando 2.000mg de sódio. A ingestão excessiva de sódio vem sendo, há muito tempo, considerada importante fator no desenvolvimento e na intensidade da hipertensão arterial. Sarno et al. ${ }^{21}$ encontraram prevalência de hipertensão arterial de aproximadamente $30 \%$ em trabalhadores beneficiados pelo PAT na cidade de São Paulo.

Frantz et al. ${ }^{22}$ desenvolveram um método de controle de sal e sódio na produção de refeições. A utilização deste método poderá contribuir com a oferta de refeições nutricional e sensorialmente adequadas com relação ao teor de sal e sódio, viabilizando ações de prevenção de doenças crônicas não transmissíveis.

Com relação à oferta de fibras alimentares, observou-se que esta foi superior ao estabelecido pelo programa. Nos estudos de Savio et al. ${ }^{23}$ e Amorim et al., ${ }^{15}$ os valores encontrados foram de 7, $1 \mathrm{~g}$ e $10 \mathrm{~g}$, respectivamente. Já Vanin et al. ${ }^{14}$ constataram que os usuários consumiam apenas $26 \%$ dos valores de fibras alimentares recomendados pelo PAT. No presente estudo, constatou-se que maioria das refeições apresentou quantidades adequadas de fibras alimentares (tabela 2). Esta adequação pode ser explicada pelo consumo de feijão e pela oferta diária de hortaliças na refeição, sendo ofertadas diariamente três tipos de saladas para os colaboradores. 
Segundo a tabela 1, a ingestão de frutas, legumes e verduras mostrou-se adequada à recomendação da OMS. ${ }^{8}$ Alguns estudos têm mostrado baixo consumo de frutas e hortaliças, como o de Bandoni et al., em que 63,9\% dos cardápios apresentaram-se inadequados em relação à oferta de frutas e hortaliças. No presente estudo, em relação à refeição oferecida para cada colaborador, verificou-se $50 \%$ de adequação.

Evidências científicas demonstraram que frutas, legumes e verduras são importantes componentes de uma alimentação saudável, podendo auxiliar na prevenção das doenças crônicas não transmissíveis. De acordo com o Relatório da Organização Mundial da Saúde (OMS) de 2002, o baixo consumo desses alimentos pode estar associado ao maior risco de doenças crônicas não transmissíveis. Estima-se que mais de 2,7 milhões de vidas poderiam ser potencialmente salvas, a cada ano, se o consumo de frutas, legumes e verduras fosse aumentado. ${ }^{16}$

\section{Conclusão}

Os resultados do presente estudo mostraram que as refeições ofertadas estão em desacordo com as recomendações do PAT em relação a alguns nutrientes. É importante ressaltar que todos os nutrientes devem estar presentes em todas as refeições, nas quantidades e percentuais recomendados, com o objetivo de promover a alimentação saudável no ambiente do trabalho.

É necessário, assim, desenvolver ações educativas focando a mudança do estilo de vida e conscientizando sobre a importância de hábitos alimentares saudáveis, já que o próprio trabalhador se serve das preparações, estipulando seu porcionamento.

Considerando que o local de trabalho é um contexto social onde o comportamento do trabalhador em relação à saúde pode ser estimulado e mantido, é imprescindível que os gestores das empresas e os responsáveis técnicos pelas Unidades de Alimentação e Nutrição cadastradas no PAT sejam sensibilizados com relação à oportunidade que esse ambiente oferece para promover a saúde dos trabalhadores.

\section{Referências}

1. Santos LMP, Araújo MPN, Martins MC, Veloso IS, Assunção MP, Santos SMC. Avaliação de políticas públicas de segurança alimentar e combate à fome no período 1995-2002. 2 - Programa de Alimentação do Trabalhador. Cad. Saúde Pública 2007; 23(8):1931-1945.

2. Bandoni DH, Brasil BG, Jaime PC. Programa de Alimentação do Trabalhador: representações sociais dos gestores locais. Rev. Saúde Pública 2006; 40(5):838. 
3. Maranhão PA, Vasconcelos RM. Análise do cardápio servido no almoço de uma UAN de acordo com o Programa de Alimentação do Trabalhador (PAT). Rev. Nutrição em Pauta 2008; 88:56-61.

4. Bandoni DH, Geraldo APG, Jaime PC. Aspectos dietéticos das refeições oferecidas por empresas participantes do Programa de Alimentação do Trabalhador na cidade de São Paulo, Brasil. Rev. Panamericana de Salud Pública 2008; 23(1):21-24.

5. Brasil. Portaria Interministerial n-66, de 28 de agosto de 2006. Altera os parâmetros nutricionais do Programa de Alimentação do Trabalhador (PAT). Diário Oficial da União 28 ago. 2006. acesso 18 maio 2012. Disponível em: http://www.mte.gov.br/legislação/portarias/2006/ /p_20060825_66.pdf.

6. Universidade Estadual de Campinas TACO. Tabela Brasileira de Composição de Alimentos. Versão 2. 2 ed. Campinas, SP: Unicamp; 2006.

7. Pinheiro ABV, Lacerda EMA, Benzecry EH, Gomes MCS, Costa VM. Tabela para avaliação de consumo alimentar em medidas caseiras. 5 ed. São Paulo: Atheneu; 2005.

8. World Health Organization. Diet, nutrition and the prevention of chronic diseases. Report of a joint WHO/FAO Expert Consultation. Genebra: WHO; 2003. (Technical Report Series, nº 916).

9. Instituto Brasileiro de Geografia e Estatística. Pesquisa de orçamentos familiares (POF) 20082009: análise do consumo alimentar no Brasil [Internet]. Rio de Janeiro: IBGE; 2010. acesso: 25 jun. 2012. Disponível em: http://www.ibge.gov.br/home/estatistica/populacao/condicaodevida/ pof/2008_2009_analise_consumo/

10. Mattos PF. Avaliação da adequação do almoço de uma unidade de alimentação e nutrição (UAN) ao Programa de Alimentação do Trabalhador (PAT). Cadernos UNIFOA 2008; 7:54-59.

11. Costa MC. Práticas alimentares, sobrepeso e perfil lipídico dos trabalhadores de uma indústria petroquímica, Camaçari - Bahia [dissertação]. Salvador: Programa de Pós-Graduação da Escola de Nutrição da Universidade Federal da Bahia; 2000.

12. Castro MBT, Anjos LA, Lourenço PM. Padrão dietético e estado nutricional de operários de uma empresa metalúrgica do Rio de Janeiro, Brasil. Cad. Saúde Pública 2004; 20(4):926-934.

13. Vanin M, Southier N, Novello D, Francischetti VA. Adequação nutricional do almoço de uma Unidade de Alimentação e Nutrição de Guarapuava - PR. Rev. Salus 2007; 1(1):31-38.

14. Souza FA, Silva RCO, Fernandes CE. Avaliação nutricional de cardápios em unidades de alimentação e nutrição: adequação ao Programa de Alimentação do Trabalhador. Veredas Favip - Revista Eletrônica de Ciências 2009; 2(1-2):43-50.

15. Amorim MMA, Junqueira RG, Jokl L. Adequação nutricional do almoço self-service de uma empresa de Santa Luzia, MG. Rev. Nutrição 2005; 18(1):145-156.

16. Oliveira CS, Alves FS. Educação nutricional em unidade de alimentação e nutrição, direcionada para consumo de pratos proteicos: um estudo de caso. Rev. Alimentação e Nutrição, Araraquara 2008;19(4):435-440.

17. Rocha R, Paiva CC, Lipi M. Avaliação dos cardápios oferecidos aos trabalhadores de empresas da região do grande $\mathrm{ABC}$ em relação às exigências nutricionais do Programa de Alimentação do Trabalhador (PAT). Revista da Associação Brasileira de Nutrição: anais do XX Congresso Brasileiro de Nutrição 2008;1(1):18. 
18. Amorim MMA, Junqueira RG, Jokl L. Consumo de óleo e gordura nas preparações do almoço self service. Rev. Alimentação e Nutrição 2010; 21(2):217-223.

19. Salas CKTS, Spinelli MGN, Kawashima LM, Ueda AM. Teores de sódio e lipídios em refeições almoço consumidas por trabalhadores de uma empresa do município de Suzano, SP. Rev. Nutr. 2009; 22(3):331-339.

20. Martins CA, Goedert B, Lima JH. Oferta de sal/sódio em preparações do almoço de uma unidade de alimentação e nutrição hospitalar em Florianópolis, SC. In: World Nutrition Rio 2012. Conhecimento Política Ação; 27-30 abr. 2012; Rio de Janeiro.

21. Sarno F, Bandoni DH, Jaime P C. Excesso de peso e hipertensão arterial em trabalhadores de empresas beneficiadas pelo Programa de Alimentação do Trabalhador. Rev. Bras. Epidemiol. 2008; 11(3):454.

22. Frantz CB, Veiros MB, Proença RPC, Sousa AA. Development of a method for controlling salt and sodium use during meal preparation for food services. Rev. Nutr. [online] 2013; 26(1):75-87.

23. Sávio KEO, Costa THM, Miazaki E, Schmitz BAS. Avaliação do almoço servido a participantes do Programa de Alimentação do Trabalhador. Rev. Saúde Pública 2005; 39(2):149.

Recebido: 05/7/2014

Revisado: 23/9/2014

Aprovado: 04/11/2014 